\title{
OS TUTORES DO PROFORMAR E A EDUCAÇÃO PROFISSIONAL DOS AGENTES DE SAÚDE PÚBLICA:TRABALHO, MEIO AMBIENTE, EDUCAÇÃO E SAÚDE
}

\author{
PROFORMAR TUTORS AND THE PUBLIC HEALTH AGENTS' PROFESSIONAL \\ EDUCATION:WORK, ENVIRONMENT, EDUCATION AND HEALTH
}

Maria Auxiliadora Bessa Barroso 1

Resumo Este estudo se propõe a analisar as concepções de educação profissional dos agentes de saúde pública (ASP) presentes na formulação do Programa de Formação de Agentes Locais em Vigilância em Saúde (Proformar) e como estas concepções são apreendidas pelos tutores do referido Programa no município do Rio de Janeiro. Trata-se de uma pesquisa empírica, de abordagem qualitativa, com análise de fontes documentais e entrevistas semi-estruturadas com os tutores do Proformar lotados no município do Rio de Janeiro. Os resultados da pesquisa demonstram que o propósito do Proformar de capacitar os ASP, tornando-os vigilantes ambientais com visão crítica, é apreendido pelos tutores, entendendo que a construção da identidade do trabalhador de nível médio do Sistema Único de Saúde (SUS) ocorre no seu processo de trabalho pela compreensão do território-população, como espaço da produção social da saúde. Os tutores assimilam as concepções de educação profissional do ASP, que apontam para o rompimento do conceito de competência calcado na lógica do mercado e da produção, avançando no sentido da valorização da experiência dos trabalhadores e do seu desenvolvimento como sujeitos políticos. Palavras-chave educação profissional; Sistema Único de Saúde; trabalho e meio ambiente; vigilância em saúde.
Abstract This study proposes to analyze the conceptions of professional education for public health agents (agentes de saúde pública - ASP) that are present in the formulation of the Training Programme for Local Agents of Surveillance in Health (Proformar) and assess how well these conceptions are understood by the programme's tutors in the municipality of Rio de Janeiro. This is an empirical research, using a qualitative approach, with analysis of documentary sources and semi-structured interviews with the Proformar tutors working in Rio de Janeiro. The research results show that Proformar's objective of training the ASP to become environmental surveyors with a critical vision is understood by the tutors in so far as they understand that the construction of the identity of the Brazilian Health System's secondary level worker happens in his/her work process through the understanding of the territory-population as a space for the social production of health. The tutors assimilate the conceptions of the ASP's professional education that point to a rupture with the concept of competence based on the market/production logic and move on to an appreciation of the workers' experiences and of their development as political subjects.

Key words professional education; Brazilian Health System; work and environment; surveillance in health. 


\section{Introdução}

As reformas das políticas públicas ocorridas no país durante as duas últimas décadas têm sido alvo de intensa discussão. No âmbito da saúde, o foco do debate direciona-se para a questão da descentralização, dentro da proposta da Reforma Sanitária, ao passo que, na educação, a ênfase recai sobre a reforma educacional, implementada pela Lei 9.394/96 (LDB).

Sabe-se que o debate democrático com resultados efetivos sobre as transformações propostas pelo Movimento da Reforma Sanitária toma impulso na década de 1980 por ocasião da $8^{a}$ Conferência Nacional de Saúde (CNS) (MS, 1987), cujo relatório final subsidiou a elaboração da Seção II "Da Saúde" — da Constituição da República Federativa do Brasil. O Sistema Único de Saúde (SUS) seria o caminho que garantiria a todos os cidadãos o acesso universal e igualitário às ações e aos serviços de saúde, para a sua promoção, proteção e recuperação, tendo como diretrizes a descentralização, o atendimento integral e a participação da comunidade (Brasil, 1988).

Entretanto, decorridas quase duas décadas, o conceito ampliado de saúde formulado na $8^{\text {a }} \mathrm{CNS}^{3}$ ainda está a exigir um redirecionamento do modelo de assistência à saúde adotado no país. Permanece o modelo "médicohegemônico, baseado numa organização 'hospitalocêntrica' da assistência médica, na sofisticação tecnológica, na exacerbação da demanda espontânea e no privilegiamento do saber clínico" (MEC, 2000, p. 12). Para Teixeira, Paim e Vilasbôas (1998), o que ocorre atualmente no Brasil é uma disputa entre modelos assistenciais que apontam para a reprodução dos modelos hegemônicos médico-assistencial privativista e assistencial sanitarista.

O processo de descentralização implica reforma das instituições de saúde, incluindo-se a Fundação Nacional de Saúde (Funasa) ${ }^{4}$, que centralizava as ações de controle das endemias em todo o país. Os agentes de saúde pública $(\mathrm{ASP})^{5}$ da EPSJV, que constituem a clientela prioritária do Programa de Formação de Agentes Locais em Vigilância em Saúde (Proformar), objeto desta pesquisa, são oriundos da Superintendência de Campanhas de Saúde Pública (Sucam), a qual tinha como finalidade precípua a execução de programas de controle e erradicação das endemias de repercussão nacional e de outras ocorrências de interesse do país, no campo da saúde pública (Barroso, 1990).

O Proformar objetiva requalificar os ASP na perspectiva da vigilância da saúde e de uma educação profissional crítica. De abrangência nacional, utiliza-se da modalidade de educação a distância (intercalada com a presencial), viabilizada por seu desenho organizacional em forma de rede. Seu público-alvo constituía-se inicialmente de 68.660 profissionais (número posteriormente ampliado) das esferas federal, estadual e municipal que desenvolvem atividades de campo no controle de doenças e em epidemiologia (Gondim e Monken, 2003). 
É na intervenção do processo saúde-doença dentro de um território e de uma população que se dá a interseção do trabalho do ASP com as questões da educação e do meio ambiente, na perspectiva da vigilância em saúde, entendendo-a como uma transformação do saber e das práticas sanitárias através de um novo olhar sobre a saúde, deslocando-o da doença para as condições de vida da população (Gondim, 2002). O conceito ampliado de saúde abarca, portanto, diferentes campos do conhecimento, o que explica o caráter interdisciplinar e intersetorial do Proformar.

Segundo Castellanos e Nuñez (apud Paim, 1997, p. 11), as condições de vida expressam as condições materiais de existência dos grupos humanos de determinada sociedade, o que subentende a sua classe social, ou seja, dependem da inserção de cada grupo na estrutura de produção. “Portanto, as condições de vida são resultantes da forma como esse grupo se insere também 'no processo de reprodução da sociedade, em um momento histórico e em determinadas condições naturais"'. Paim entende que o estudo das condições de vida de grupos populacionais deve levar em consideração também as ações estatais voltadas para o atendimento das necessidades básicas da vida humana, tais como: saúde, saneamento, educação, alimentação e nutrição, lazer, segurança.

Certamente que a nova concepção de saúde vem influir na reforma da educação profissional na área da saúde, na medida em que as transformações político-administrativas ocorridas neste setor, nas quais se coloca a descentralização, exigem do trabalhador da saúde uma nova consciência do seu papel no processo de trabalho, cujos compromissos "transcendem o setorial e diversificam, tendencialmente, os seus campos de prática" (MEC, 2000, p. 13). O Ministério considera como especificidade dos trabalhadores de saúde o compromisso desses profissionais com a saúde no seu conceito ampliado, vinculando-a à questão da cidadania.

De acordo com os Referenciais Curriculares Nacionais da Educação Profissional de Nível Técnico - Área Profissional Saúde (MEC, 2000), para fazer face às atuais exigências do setor, o trabalhador precisa ser capaz de identificar situações novas, auto-organizar-se, tomar decisões, interferir no processo de trabalho, trabalhar em equipe multiprofissional e, ainda, ter capacidade de resolutividade diante de problemas emergentes. Tais exigências remetem à questão das competências, um dos eixos orientadores da proposta do Proformar.

O documento citado coloca como desafio para a Educação Profissional de Técnicos de Nível Médio para a Área de Saúde uma revisão de paradigmas e pressupostos, visando atender às demandas geradas pelo mercado hoje, e levanta as seguintes questões que as matrizes curriculares propostas pelo MEC pretendem ajudar a responder: “Quem é o técnico de nível médio na área da Saúde? Que tipo de profissional pretendemos formar? O que o 
mercado espera desse profissional? Quais as expectativas profissionais dos alunos de cursos técnicos da área de Saúde? Qual o papel desse profissional na sociedade?" (MEC, 2000, p. 15).

Apropriando-nos do questionamento levantado pelo MEC, focalizamos duas questões que julgamos mais relevantes para o estudo que nos propusemos desenvolver: que tipo de profissional pretende-se "formar"? Qual o papel desse profissional na sociedade?

Tais indagações nos levam a analisar as concepções de educação profissional dos ASP presentes na formulação do Proformar e como estas concepções são apreendidas pelos tutores do referido programa no município do Rio de Janeiro, a partir da compreensão do novo papel do ASP diante das transformações ocorridas em seu processo de trabalho. Este estudo insere-se no contexto das reformas das políticas de educação e de saúde do país, identificando-se as interseções do trabalho, meio ambiente, educação e saúde.

Trata-se de pesquisa empírica de abordagem qualitativa, com análise de fontes documentárias e entrevistas semi-estruturadas com os tutores do programa que atuam no município do Rio de Janeiro. Foram entrevistados os sete tutores do município, o que corresponde a $100 \%$ dos tutores que participaram da capacitação e permaneceram neste município. No momento da pesquisa, que se desenvolveu no período de maio a outubro de 2003, o Proformar estava em sua fase inicial de implementação e havia realizado, no estado do Rio de Janeiro, apenas uma oficina de capacitação de tutores, com 31 participantes, distribuídos em vários municípios.

\section{Interseções}

Se a interseção entre a questão do meio ambiente com o trabalho, a educação e a saúde se dá no âmbito das políticas sociais, enquanto forma de pensamento e de interação homem-sociedade-ambiente, importante se torna tecermos algumas considerações sobre o conceito e os sentidos das políticas sociais no contexto da globalização.

Viana (1997) afirma que as políticas sociais expressam um tipo específico de intervenção estatal, especialmente no período pós-guerra, e vincula as políticas sociais ao termo Welfare State - "o Estado que oferecia proteção governamental mínima em níveis de renda, alimentação, saúde, habitação e educação, assegurados a cada cidadão como um direito, não como caridade" (Wilenky, 1975, apud Viana, 1997, p. 201).

Segundo Coraggio (1996, p. 77-78), as políticas sociais podem se apresentar com três possíveis sentidos: "dar continuidade ao processo de desenvolvimento humano que ocorreu apesar da falência do processo de industrialização e desenvolvimento econômico"; "compensar conjunturalmente 
os efeitos da revolução tecnológica e econômica que caracteriza a globalização"; e "instrumentalizar a política econômica, mais do que para continuála ou compensá-la".

O autor considera que o primeiro sentido enfatiza o investimento nas pessoas, voltado para o acesso universal a um mínimo de educação, saúde, alimentação, saneamento e habitação, aumento da expectativa de vida e eqüidade na distribuição das oportunidades. Adverte, porém, que desta forma promove-se a eqüidade empobrecendo a classe média, sem afetar as classes mais favorecidas da sociedade.

Quanto ao segundo sentido das políticas sociais, Coraggio entende que as políticas sociais surgem de forma complementar, de modo a garantir a continuidade do ajuste estrutural, liberando as forças de mercado e extinguindo a cultura de direitos universais de bens e serviços assegurados pelo Estado. Critica as conseqüências que elas acarretam quando se transformam em políticas ineficientes, interferindo nas relações entre a política, a economia e a sociedade, e redundando na mercantilização da política, prejudicial ao exercício da cidadania.

A análise de Coraggio sobre o terceiro sentido enfoca a "reestruturação do governo". Ao mesmo tempo em que o descentraliza, diminui o seu tamanho, além de reproduzir nos serviços públicos os valores e critérios do mercado, tal como o critério de eficiência, o que coloca a elaboração das políticas setoriais, contraditoriamente, a serviço das políticas de ajuste estrutural.

Diante das críticas levantadas, perguntamos: qual a é política social que queremos? O próprio autor reconhece que a realidade da política social é contraditória e não é mera resultante da vontade dos que detêm o poder, "mas algo emergente no qual podem incidir a crítica do discurso dominante e a proposição de alternativas para a sociedade em seu conjunto" (Coraggio, 1996, p. 79).

Vislumbramos, assim, alguns nexos entre as considerações de Coraggio e a proposta do Proformar, na medida em que este programa, inserido no contexto da globalização e que tem como pano de fundo as reformas do Estado, aponta caminhos alternativos no campo da saúde, sem desprezar o seu caráter interdisciplinar e intersetorial. A proposta traz em seu bojo componentes da educação, enquanto programa de formação profissional que tem como referencial a LDB; componentes do trabalho, na medida em que considera os processos de trabalho e propõe mudanças de perfil e de papel de um determinado profissional da saúde; e do meio ambiente, quando na reformulação da concepção de saúde preocupa-se, sobretudo, com as condições de vida das populações. Avança ainda na temática do meio ambiente, incluindo-a na pauta de discussão e no trabalho de campo dos seus cursos e levando o agente-aluno a um novo olhar sobre as condições de vida da população da sua área de trabalho. 
Todos os componentes das políticas sociais apresentados convergem, em última instância, para uma questão fundamental que permeia a proposta do Proformar: o desenvolvimento de uma consciência crítica voltada para o exercício da cidadania, na perspectiva da formação de um trabalhador-cidadão.

Entretanto, a discussão do conceito de cidadania no contexto do meio ambiente vai além da concepção clássica, em que a garantia dos direitos por um Estado forte, pautado no Estado de Bem-Estar Social, era a garantia de uma vida digna (Loureiro, 2000). O autor reconhece os limites na conceituação de cidadania e de consciência quando se ignora o aspecto ambiental, mas considera que a superação conceitual implica a incorporação de elementos já construídos, afirmando que

\begin{abstract}
“A ecocidadania é um conceito consensualmente utilizado para expressar a inserção de uma nova ética - a ecológica - e seus desdobramentos na vida diária, em um contexto que, de modo crescente, possibilita a tomada de consciência individual e coletiva das responsabilidades, tanto locais e comunitárias, quanto globais. Nesse conceito, amplia-se o sentimento de pertencimento à humanidade e a um planeta único, comumente identificado com a noção de cidadania planetária ou cosmopolita" (Loureiro, 2000, p. 29).
\end{abstract}

A consciência de que os problemas ambientais são globais parece consenso no mundo atual, porém, no âmbito da formulação das políticas de meio ambiente e das suas práticas é uma questão ainda bastante polêmica.

Sobral (2000, p. 141) admite que "a conseqüência, talvez, mais imediata, desta preocupação com o global foi a constatação de que o enfrentamento destas questões ambientais exige, sobretudo, ações locais"'. E, neste sentido, multiplicaram-se as iniciativas em todo o mundo, inclusive de municípios e estados, com a implantação de políticas ambientais locais, além da atuação de diversas organizações não governamentais (ONG) com programas de mobilização dos cidadãos a partir de pequenos espaços de convivência. Por outro lado, a dimensão global da questão obrigou os blocos de países, reunidos em torno de aspectos meramente econômicos, a ampliarem as suas discussões, incluindo a problemática ambiental na busca da homogeneização.

Outra questão presente nos debates sobre trabalho, meio ambiente, educação e saúde consiste na mudança de seus paradigmas diante das transformações do mundo globalizado, a exigir novas concepções e novas afirmações sobre o "mundo real" e a "vida real" (Altvater, 1999, p. 110). Tais mudanças estão certamente relacionadas às crises socioambientais e do mundo do trabalho, as quais, de acordo com Deluiz e Novicki (2001), são conseqüências das atuais transformações que se processam na economia mundial. Estes autores concordam que as transformações em curso baseiam-se "na crescente integração dos mercados, nas mudanças nas estratégias de políti- 
cas econômicas e na transição do padrão da organização industrial 'taylorista-fordista' para o da acumulação flexível" (Harvey, 1996, apud Deluiz e Novicki, 2001, p. 1).

Para Sobral (2000), a política neoliberal (subjacente ao processo de globalização) foi a estratégia natural adotada para substituir a 'keynesiana', tirando assim da responsabilidade do Estado o fardo dos programas sociais e ambientais. Sob esta ótica, a solução dos problemas socioambientais fica subordinada às leis do mercado, liberando o Estado das atividades de controle ambiental e restringindo a sua ação às políticas sociais focalizadas.

Ao se referir às reformas nos sistemas públicos de ensino, Di Pierro (2001, p. 323) afirma que a proposta neoliberal, na perspectiva da redefinição do papel do Estado e do ajuste macroeconômico, objetiva racionalizar os gastos públicos, aumentando ao mesmo tempo a eficiência e a eficácia do sistema de ensino. A autora apresenta os "vetores" da proposta neoliberal, seguidos pela reforma educacional, comuns às demais políticas sociais públicas: "descentralização da gestão e do financiamento; focalização dos programas e populações beneficiárias; privatização seletiva dos serviços e desregulamentação".

Comungando desta concepção, Mendes (1999), se reporta à hegemonia do projeto neoliberal da saúde, afirmando que, no campo das políticas sociais, as estratégias de estabilização ou de ajustes neoliberais assentam-se em três opções: a privatização, a descentralização e a focalização. Entende que a privatização dos serviços sociais dá-se de forma injusta, visto que, além de remeter a regulação a mecanismos de mercado, com prejuízo das classes menos favorecidas, as empresas privadas são geralmente beneficiadas com subsídios estatais. Compreende a descentralização como forma de aumentar a eficácia e a eficiência dos gastos sociais, em busca de um Estado mínimo, e a focalização, como decorrência dos parcos gastos sociais públicos com setores pobres da sociedade, priorizando os recursos para os programas sociais assistenciais.

Entendemos, assim, que é na interação Estado-sociedade, permeada pelas formas de organização social da produção de bens e serviços e das relações que as envolvem, que se processa a interseção entre educação, trabalho, saúde e meio ambiente. E a reestruturação do papel do Estado, no contexto da globalização, atinge profundamente esses campos do conhecimento, quer na construção e reelaboração de seus saberes, quer na formulação de suas políticas ou nas práticas de seus atores sociais, em que se incluem os Agentes de Saúde Pública.

\section{Vigilância da Saúde}

A proposta do Proformar fundamenta-se no quadro teórico-conceitual da Vigilância da Saúde (VS), vista como eixo de um processo de reorientação 
dos 'atuais modelos assistenciais'6 do SUS (EPSJV, 2002). A nova concepção da VS supera a visão biologicista do processo saúde-doença, extrapolando o plano setorial e articulando-se com outros campos do conhecimento, levando em consideração as dimensões histórica e socioambiental da população:

“A VS vê a saúde e a doença como resultantes dos processos sociais que ocorrem no seio de uma dada formação histórica, expressas num estado de bem-estar, que pode indicar acúmulos positivos e/ou negativos. Ao compreender a dinâmica das interações sócio-ambientais que ocorrem em uma população e em um território, encontra os elementos essenciais que definem as necessidades de cuidados de uma população" (EPSJV, 2002, p. 2).

Sob essa ótica, a VS reconhece os condicionantes socioeconômicos e políticos nas situações de saúde, o que envolve questões relacionadas às desigualdades e iniqüidades sociais. Transcende, portanto, o modelo da multicausalidade centrado na doença e em seus agentes causais, o qual, segundo Barreto e Carmo (1995), apesar de sua importância científica, tem se mostrado insuficiente.

A partir das interligações entre saúde do trabalhador e meio ambiente, Stotz (1994) discute essa questão, contribuindo para o debate sobre o processo saúde-doença numa visão mais ampla, que, além da compreensão multicausal, abrange as relações constituintes no nível da sociedade.

A mudança do foco do objeto da saúde pública da doença para as condições de vida das populações é que norteia a concepção da proposta do Proformar, incorporando alguns aspectos imanentes à VS: a interdisciplinaridade, que se baseia na premissa de que os acontecimentos que afetam a qualidade de vida das populações decorrem de interações e situações diversas, necessitando para a sua apreensão de um "olhar plural" sobre a realidade e os fatos; o planejamento estratégico, como ferramenta básica, e a territorialização, como "processo que tem por objetivo espacializar elementos e relações importantes de uma população - ecológicos e ambientais — os quais traduzem no espaço a forma de sua organização (modo e estilo de vida) e determinam em maior ou menor escala seu grau de qualidade de vida" (Gondim, 2002, p. 2-3).

A 'qualidade de vida' é considerada por Minayo (2004, p. 7) como um conceito subjacente ao enfoque ecossistêmico de saúde, afirmando que "ele se funda na compreensão de um processo de construção de novas subjetividades pela participação em projetos de mudanças, numa ótica de desenvolvimento sustentável e de cumplicidade com as gerações presentes e futuras".

O conceito de territorialização é coerente com o pensamento de Paim (1997), que coloca como alternativa teórico-metodológica para a análise das necessidades e das desigualdades sociais da saúde a inserção espacial dos gru- 
pos humanos no território, numa perspectiva histórico-social, além dos limites da dimensão física ou natural.

O território enquanto espaço que se traduz no ambiente físico, social e cultural é também, segundo Valla e Stotz (1994, p. 100), 'lugar' de "reprodução da força de trabalho" e de "referência social" e, portanto, revela percepções, crenças e discursos que variam de acordo com cada situação vivenciada nesses "'lugares' sociais de reprodução".

Subjacente à proposta da vigilância da saúde, cresce o debate em torno da questão da promoção da saúde, na busca de um novo paradigma que abarque o ambiente local e global, na perspectiva do bem-estar individual e social. Analisando o discurso em torno da promoção da saúde, particularmente nas discussões desenvolvidas nas conferências internacionais sobre o tema?, Buss (2003, p. 15) constatou que "a promoção da saúde propõe a articulação de saberes técnicos e populares e a mobilização de recursos institucionais e comunitários, públicos e privados para o seu enfrentamento e resolução".

A promoção da saúde traz em seu bojo algumas questões polêmicas. Segundo Czeresnia (2003), por um lado, apresenta-se como um movimento calcado na racionalização de recursos, motivado pela necessidade de conter o fluxo crescente de verbas destinadas à assistência médica, e por outro, apresenta uma dimensão de caráter progressista, que aponta para a criação de políticas públicas intersetoriais, com vistas à melhoria da qualidade de vida das populações.

\section{O modelo das competências}

Dentre os conceitos aqui utilizados para coletar e analisar os dados empíricos relacionados à educação profissional, destacamos a noção de 'competência', cuja discussão envolve referências à política nacional de educação profissional do ASP e à definição do papel desse agente.

A política nacional de educação profissional do ASP, apontada pelo Proformar, procura romper com formas arcaicas de formação desse agente desenvolvidas no interior de sua instituição. Procura avançar no sentido da sua profissionalização, dentro da nova realidade do SUS, na perspectiva da formação por competência (EPSJV, 2001).

O papel do ASP, nesse contexto, implica busca de uma nova identidade, frente às transformações ocorridas no seu processo de trabalho. O Proformar propicia essa reconstrução, de maneira compartilhada, ao mesmo tempo em que contribui para a formulação de uma política nacional de formação profissional para esse trabalhador da saúde.

Não pretendemos aqui nos aprofundar na análise do termo competência, cuja característica polissêmica levou Perrenoud (1999, p. 19) a usar a ex- 
pressão “Torre de Babel" em alusão ao seu significado. Para efeitos deste artigo, importa, sobretudo, identificar alguns referenciais utilizados na elaboração da proposta do Proformar que vão orientar a análise das percepções dos tutores sobre a questão.

O Proformar utiliza o referencial de Ramos que critica a fragmentação do conhecimento em compartimentos disciplinares e defende um currículo que ressalte a "experiência concreta dos sujeitos como situações significativas de aprendizagem" (EPSJV, 2002, p. 8). Ramos destaca três noções de competência:

“Entendemos por competência os esquemas mentais, ou seja, as ações e operações mentais de caráter cognitivo, sócio-afetivo ou psicomotor que mobilizadas e associadas a saberes teóricos ou experiências geram habilidades, ou seja, um saber fazer" (Berger, 1998, apud Ramos, 2001a, p. 163).

“(...) a capacidade que os trabalhadores têm de enfrentar situações e acontecimentos próprios de um campo profissional, com iniciativa e responsabilidade guiados por uma inteligência prática do que está ocorrendo e coordenando-se com outros atores para mobilizar suas próprias capacidades" (Zarifian, 1999, apud Ramos, 2001a, p. 66).

"São as modalidades estruturais da inteligência, ou melhor, ações e operações que utilizamos para estabelecer relações com e entre objetos, situações, fenômenos e pessoas que desejamos conhecer" (Brasil, MEC/Enem - Documento Básico 2000, apud Ramos, 2001a, p. 163).

O modelo das competências, no contexto da educação profissional, tem origem no debate em torno das qualificações diante do novo paradigma produtivo da 'especialização flexível', o que resultou em profundas transformações no mundo do trabalho. Tal paradigma é representado pelo modelo japonês e se caracteriza principalmente pelo trabalho em equipe e pela polivalência e multifuncionalidade do trabalhador. Subtende novas exigências de qualificação, no sentido de desenvolver capacidades de julgamento, discernimento e resolutividade (Hirata, 1999).

A qualificação do trabalhador, citada por Hirata, envolve a "qualificação real" como conjunto de competências e habilidades - técnicas, profissionais, escolares e sociais - e a "qualificação operatória" como "potencialidades empregadas por um operador para enfrentar uma situação de trabalho" (Sailly, 1992, apud Hirata, 1999, p. 132).

A qualificação real, em contraposição à qualificação formal, é destacada no modelo de flexibilização e integração dos processos produtivos, quando se passou a valorizar a subjetividade e o saber tácito do trabalhador: 
“A partir de então, firmou-se um certo consenso sobre a idéia de que a construção de aprendizados deve ir além de conhecimentos academicamente validados, mas construir saberes também a partir das mais diversificadas experiências que o sujeito enfrenta, seja no meio de trabalho, seja na sua vida em geral, seja na escola. É nesse contexto que surge a noção de competência, que hoje mobiliza um conjunto de sujeitos sociais tanto com o propósito de compreender seu significado quanto para implementar ações que a tenham como base" (Ramos, 2001b, p. 18).

Desta forma, pensar na perspectiva de sua formação é pensar numa organização curricular flexível e por competências. Porém, competências que estejam voltadas para o crescimento profissional e pessoal do trabalhador de saúde, inclusive na sua condição de cidadão. Significa dizer que as competências, de acordo com o pensamento de Deluiz (2001 p. 14), "não podem se restringir à dimensão técnico-instrumental, tornando-se uma simples estratégia de adaptação às novas necessidades do processo produtivo, mas devem ser consideradas de forma ampliada, no sentido de abranger a dimensão ético-política do mundo do trabalho".

A qualificação real, segundo Deluiz (1996, p. 2), caracteriza-se por um conjunto de competências posto em ação em uma situação concreta de trabalho que consiste mais em "saber ser" do que em "saber fazer".

Assim, os conceitos relativos à educação profissional que deram sustentação à coleta e à análise dos dados empíricos desta pesquisa estão presentes tanto na formulação da proposta do Proformar, como na fala dos tutores, conforme veremos a seguir.

\section{Resultados}

Os diálogos desenvolvidos com os tutores do Proformar sobre o papel do ASP, a partir das considerações sobre o seu perfil, nos levam a inferir que o conceito que eles têm do agente varia em função do maior ou menor contato entre tutor e agente: do conhecer 'apenas de vista' até um conhecimento mais estreito adquirido na convivência de trabalho. Distinguimos assim dois grupos de tutores: um constituído de profissionais fora dos quadros da Funasa e outro composto de funcionários do quadro da Funasa, os quais pertencem oficialmente à mesma categoria do ASP, mas desenvolvendo atividades diferenciadas.

No primeiro grupo, há tutores com experiência em atividades de formação profissional, identificando-se um discurso mais direcionado ao agente-aluno, enquanto no segundo, onde se encontram tutores com vivência de trabalho de campo no controle das endemias, o foco de suas preocupações volta-se para o agente-trabalhador. 
O primeiro grupo caracteriza o agente a partir de questões objetivas, tais como escolaridade, situação econômica, tempo de serviço, enquanto no segundo grupo aparecem conceitos que enfatizam a subjetividade do ASP, como a auto-estima, o sentimento de insegurança e outras manifestações decorrentes de pressões sofridas pelos agentes diante das mudanças que afetam a sua vida de trabalhador:

“Não tenho vivência com este tipo de agente; vejo aqui, os 'mata-mosquitos' que trabalham aí embaixo, mas nunca trabalhei com eles. Mas o que sei é que são pessoas que só tem nível médio, a maioria não tem nível superior; são pessoas com dificuldades econômicas"' (entrevistado 1).

“É um agente que vem ao longo do tempo sendo desprestigiado pela própria instituição; é cada vez mais requisitado e cobrado no campo; tem sofrido pressão, a cada hora vem uma notícia de que ele pode ser enquadrado como nível auxiliar e ele tem que estudar pra poder não perder dinheiro" (entrevistado 4).

Há consenso entre os tutores de que as atividades do ASP se dão de forma fragmentada, direcionadas ao controle de determinada doença, sem uma visão de totalidade na relação saúde-doença:

\footnotetext{
"Esses guardas, antigos guardas de endemias, e os diversos nomes que lhes eram dados, eram trabalhadores que faziam trabalhos assim muito pontuais. Por exemplo, quem trabalhava com a dengue, só sabia dengue, quem trabalhava com malária, só sabia malária, quem trabalhava com saneamento, só sabia saneamento" (entrevistado 2).
}

“Pelo que eu tenho visto, pela informação que eu tenho recebido do pessoal que está trabalhando descentralizado, no estado eles estão vinculados a uma secretaria, mas ligados ao dengue ainda, e no município, ligados ao controle dos vetores, também ligados ou à leishmaniose ou à questão do dengue... a visão de saúde ampliada, o conceito de vigilância ambiental, eles não estão desenvolvendo, estão desenvolvendo atividades específicas ainda" (entrevistado 4).

Entendemos que as ações isoladas dos ASP, do modo como foram colocadas pelos tutores, estão intrinsecamente relacionadas ao modelo de atenção à saúde ainda vigente no país, que, segundo Teixeira, Paim e Vilasbôas (1998), corresponde ao modelo médico-assistencial privatista que convive com o modelo assistencial sanitarista. Assim, os programas de controle das endemias, que se enquadram no modelo sanitarista, ainda adotam uma metodologia verticalizada, obedecendo a normas técnicas emanadas do nível central. 
O papel do ASP, na concepção dos tutores, fundamenta-se no referencial da vigilância e da promoção da saúde, o que implica mudança de uma prática fragmentada para uma prática integrada, em que o agente perceba a importância e o significado de suas tarefas, tanto na sua inserção no âmbito do SUS, como dentro de um conjunto mais amplo da sua realidade de trabalho:

\begin{abstract}
“Ele vai ter um papel decisivo que é de construir um outro referencial, que é um referencial que está colocado em termos teóricos, mas ainda não está posto na realidade. Que é o referencial da promoção da saúde, da vigilância da saúde, trabalhando com a perspectiva da intersetorialidade (...) desde o movimento da Reforma Sanitária, o movimento sanitário avançou para uma proposta de promoção da saúde, de vigilância, que é um outro paradigma, um outro referencial, isso ainda não se traduziu em mudança no serviço" (entrevistado 2).
\end{abstract}

"Como pilar de todo o sistema de saúde, que tem o contato mais direto com a população, que aponta todo o sistema de referência é muito importante como ele vai trazer para população a visão do sistema de saúde, e pra sua própria prática também, pra ele não ser apenas um agente mecânico ou alienado" (entrevistado 1).

Vale salientar que, com base na legislação da Educação Profissional (MEC, 2001), o curso do Proformar, sendo de nível básico, não tem a finalidade de proporcionar a formação de profissionais no sentido oficial do termo, ou seja, não se trata de curso de formação. Objetiva conferir qualificação e atualizar esses trabalhadores da saúde com vistas à sua inserção numa nova proposta de trabalho e à melhoria do seu desempenho profissional. Quando utilizamos o termo 'formação', o fazemos em função do termo adotado pelo próprio programa em estudo: Programa de Formação de Agentes Locais em Vigilância em Saúde. Subtende-se a educação profissional enquanto processo de formação de um trabalhador cidadão, como bem se expressa um tutor:

“Pela legislação, claro que 'formação' é só a nível de segundo grau. Mas se a gente entende que a educação está formando, então é na perspectiva de que você está formando mesmo esse trabalhador cidadão (...). Mas na realidade está formando, entre aspas, um profissional, um trabalhador que vai ser colocado no mercado e vai ter um papel decisivo" (entrevistado 2).

A compreensão dos tutores quanto aos objetivos da formação do ASP está relacionada ao novo papel desse agente no contexto da descentralização das ações de saúde. Assim, os tutores entendem que o curso, muito mais do que preparar o agente para ações específicas, pretende formar uma nova consciência do seu papel, voltada para a reconstrução de sua identidade 
dentro de uma concepção ampliada de saúde na perspectiva de uma educação transformadora:

“É prepará-lo para ações específicas na área de saúde e mais ainda, é dar-lhe uma visão ampla do que seja a saúde, de sua inserção dentro do Sistema Único de Saúde" (entrevistado 1).

“Eu acredito na educação como possibilidade de transformação, seja em que nível for. Qualquer trabalhador que esteja sendo formado, eu acho que é nessa perspectiva de estar contribuindo para a mudança da sociedade. Eu acho que a educação tem que ter essa perspectiva de transformação: transformação política, transformação social, transformação ética e transformação a nível também de conhecimentos. A gente precisa avançar na situação de saúde da população. Então, esses trabalhadores são fundamentais" (entrevistado 2).

A proposta do Proformar, calcada no referencial da vigilância da saúde, vem acrescentar um novo componente à formação e à prática do ASP - a preocupação com o meio ambiente - ampliando-se assim o seu conceito de cidadania com a inserção da "ética ecológica" (Loureiro, 2000, p. 29). O discurso que permeia os documentos do Proformar aponta nessa direção e o desenho do curso pretende concretizá-lo apresentando um módulo intitulado “Trabalho e ambientes saudáveis" (EPSJV, 2002, p. 14).

No entanto, ainda não está bem claro para os tutores como esta questão vai ser conduzida na prática. Um dos tutores entrevistados tenta visualizar uma situação, desenvolvendo, ao mesmo tempo, uma reflexão sobre como seria a ação do agente nessa perspectiva:

“Então ele chega numa casa, ele vai ver tudo o que envolve a vigilância naquela casa, porque antes ele ia só pra ver se tinha mosquito pra dengue. Agora não, ele chega lá, ele vê as condições de habitação, a questão do esgoto, a questão do lixo. Vamos supor que tenha uma criação de porcos no local, ele vai ver, vamos supor que tenha uma horta que está contaminada com uma fossa contaminada, estão fazendo queimadas..." (entrevistado 2).

“(...) agora, o nível de intervenção me parece que cada profissional tem um nível de intervenção. Por exemplo, se for uma intervenção que precise multar, a pessoa está criando porcos no quintal, isto tem riscos, qual é o procedimento? Primeiro orientar, primeiro esclarecer, a competência de multa não é dele..." (entrevistado 2).

“(...) a formação de agente é uma formação que não confere um conteúdo técnico muito aprofundado em todas essas ações, e nem poderia com uma carga horária dessa, e com uma escolaridade dessa. Quem dominaria essa amplitude toda seria 
um técnico... mas mesmo assim, algumas ações ele não pode fazer, ele não tem poder de multar, ou advertir, interditar" (entrevistado 2).

Alguns tutores acreditam que a mudança de papel do ASP produzirá um impacto na saúde da população. Outros colocam, de forma enfática, a importância do Proformar na mudança do modelo assistencial vigente para o enfoque da vigilância da saúde:

“É o impacto que isso vai ter na saúde da população. Porque você vai ter um agente que vai estar ali trabalhando no controle de uma determinada endemia, mas ele vai estar antenado pra todos os problemas de saúde que estão ocorrendo ali. Então, muitas vezes ele vai detectar coisas relativas à vigilância sanitária, vai detectar coisas que são de outros setores da saúde, e ele vai ter noção de que informar e acionar esses outros setores é responsabilidade dele também" (entrevistado 5).

“Eu acho que a importância é enorme desse programa, porque a idéia é justamente mudar mesmo, mudar o paradigma mesmo, é parar uma coisa e iniciar outra de uma maneira completamente diferente, bem mais positiva, acho eu" (entrevistado 6).

A intenção de mudança de paradigma está implícita em documentos oficiais do Ministério da Educação (MEC, 2000), representando um avanço na concepção de saúde por parte das instituições que conduzem as políticas de educação profissional no país:

“O reconhecimento da integralidade como um princípio ou diretriz que contemple as dimensões biológicas, psicológicas e sociais do processo saúde-doença mediante a promoção, proteção e reabilitação, visando à integralidade do ser humano, deve ser difundido como uma nova cultura da saúde na educação profissional" (MEC, 2000, p. 13).

Apesar de se identificarem, nesses referenciais, princípios contidos na proposta do Proformar (EPSJV, 2002), a pesquisa revela o descompasso entre o discurso e a prática, inclusive de natureza normativa, uma vez que, nas ações dos programas de controle de endemias, mesmo após a municipalização, seguem-se normas técnicas rígidas do nível central que dificultam uma ação mais ampliada e mais integrada, o que deixa perplexo o tutor com vivência nesse campo.

“Então quando eu falo a você que as diretrizes pra mim são divergentes é porque a Funasa tem manuais de normas técnicas para cada endemia, porque é onde está lotado cada grupo de servidores. Quando você traz o Proformar, você não traz uma endemia específica, traz um corpo geral, e o que o servidor da Funasa trabalha? 
O que ele tem são suas endemias que ele trabalha lá... Como é que eu vou conseguir transformar esse servidor, que tem essa especificidade técnica de cada manual, de cada endemia, pra trabalhar numa abrangência total?" (entrevistado 7).

A defasagem entre a concepção e a execução da proposta constitui uma preocupação geral dos tutores, os quais reconhecem a necessidade de mudanças na esfera da gestão dos serviços, o que significa que as transformações esperadas precisam ser trabalhadas em nível de decisão, traduzindo-se em vontade política local, a exigir, sobretudo, mudança de mentalidade:

“Ele [o agente] sozinho não vai conseguir, precisa também de uma mudança de concepção em nível de gestores... É porque esse movimento tem duas vertentes: tem a vertente da formação e tem a vertente da gestão do trabalho em saúde. Os dois são importantes, os dois são fundamentais. Mas precisa de alguma forma que esse movimento trabalhe com gestores nessa nova perspectiva, nesse novo modelo de vigilância, de promoção da saúde, do contrário isso vai ser um trabalho que, infelizmente, não vai dar os frutos que a gente espera" (entrevistado 2).

"Eu e alguns outros tutores procuramos discutir já isso, até na própria capacitação dos tutores, que a gente precisa trabalhar mais os gestores, para estar utilizando melhor esse pessoal, essas informações (...) a preocupação nossa é que quando nós formarmos, se ele não continuar fazendo, ele vai sair talvez mais traumatizado do que se não tivesse feito o curso, porque ele vai ser capacitado pra fazer uma coisa e não vai conseguir transmitir pra alguém... Então a nossa preocupação qual é? É o gestor, nós temos que trabalhar muito o gestor municipal pra que ele possa usar essa mão de obra" (entrevistado 7).

Há ainda entre os tutores (do quadro da Funasa) quem expresse grande inquietação com a implementação da nova proposta no que tange à redefinição do papel do ASP, o que indica a ausência (ou pouca clareza) de diretrizes do Ministério da Saúde com relação à política de recursos humanos de seus servidores. O clima de apreensão e de incerteza que acompanha o processo de descentralização pode revelar também a negação do direito de acesso à informação, diante da ausência de canais de comunicação intrainstitucionais:

“Existe uma outra preocupação com relação a isso: o que é que o Ministério pretende com isso? Pretende transformar as funções dos servidores? Vai modificar isso pra alguma outra coisa? Ele vai deixar de ser agente de saúde ou guarda de endemias? Vai passar a ser um agente de vigilância sanitária, um Avisa? Qual será a função de cada servidor desse? É uma coisa que pra gente é uma incógnita, e existe muito receio do que vem do Ministério pra gente" (entrevistado 7). 
Para alguns, tal situação é extremamente incômoda, sobretudo pela possibilidade de resultar em cobranças capazes de comprometer a sua credibilidade perante os agentes de saúde. É o que podemos extrair da fala de um tutor, dentre outras que apresentam essa preocupação:

“Depois de 'formado', o que fará esse profissional? Eu quero que ele tenha uma visão ampla, modificada, abrangente, que ele seja um identificador de situações, que ele busque soluções, mas será que ele vai ter espaço, no meio onde trabalha, pra botar em prática isso? Será que vão querer esse profissional qualificado por perto? Tem muito lugar que não quer, então é esse o nosso problema... Em que irão se transformar? Muda a função no contracheque? No pagamento, muda alguma coisa pra eles?" (entrevistado 7)

"De que adianta você motivar o trabalhador, modificar a maneira dele de pensar, de agir, de verificar as situações (...) a gente pretende formar esse projeto, fazer que ele traga soluções, que ele construa uma melhoria no seu ambiente de trabalho ou de moradia, agora quem vai apresentar essa proposta? Será que vai ser aceita? será que deixarão ele continuar trabalhando com essa metodologia, com essa proposta?" (entrevistado 7).

Admitindo, de antemão, que no âmbito da gestão dos serviços a proposta pode não ter respaldo, pelo menos de imediato, os tutores entendem que a formação do ASP tem a função, sobretudo, de "formar uma massa crítica" (entrevistados 2 e 5) com poder de pressão.

A construção, no município, de um modelo fundamentado na vigilância da saúde, segundo Teixeira, Paim e Vilasbôas (1998), torna-se viável a partir da Norma Operacional Básica (NOB) n ${ }^{\circ} 001 / 96$, que ensejou a criação de instrumentos financeiros, gerenciais e técnico-operacionais que propiciam a reorientação do modelo assistencial do SUS.

O Proformar, coerente com a proposta do novo papel e da nova identidade do ASP, aponta para uma mudança de paradigma também da metodologia dos cursos: da forma tradicional dos treinamentos realizados pela Funasa, que priorizava os conteúdos técnicos centrados no controle de uma determinada endemia, para uma abordagem mais ampla que considera, inclusive, a dimensão ecológica da ação desse agente. Pretende, portanto, na visão dos tutores, preparar esse agente para ser um "observador", um "identificador de problemas", um "articulador", um "educador":

“Não é fazer um treinamento, é qualificar o profissional, é preparar esse profissional pra ele observar toda a situação que está envolvendo o trabalho dele. É mesmo fazer com que esse profissional veja a situação geral do lugar, e não só determinar aquela coisa específica de que foi treinado pra fazer, é que ele faça sim, 
da maneira correta, mas sabendo porque ele está fazendo aquilo, para que ele está fazendo aquilo" (entrevistado 6).

"Eu quero que ele tenha uma visão ampla, modificada, abrangente, que ele seja um identificador de situações que ele busque soluções" (entrevistado 7).

"Desenvolver em cada indivíduo as condições para que ele possa observar e buscar soluções para aqueles problemas que ele vê que tem na sua região, e não só o problema direcionado" (entrevistado 5).

“Ele vai ser um grande articulador no nível local do SUS, promover a intersetorialidade, então, ele vai ser um agente que vai estar atento a todos os problemas de saúde" (entrevistado 3).

“Na nossa ótica ele não vai mais ter só que bater palmas, receber a pessoa, entrar na sua casa e fazer o seu trabalho de combate ao vetor da dengue nos depósitos com água, mas trazer mais informações, orientar melhor aquele morador até sobre sua própria saúde e condições de vida" (entrevistado 7).

“Então esse agente vai ter um papel fundamental como promotor dessas mudanças" (entrevistado 2).

A visão dos tutores com relação ao papel do agente local de vigilância em saúde no SUS está, pois, absolutamente coerente com o concebido pelo Proformar: "Ser o interlocutor do Sistema Único de Saúde (SUS) e da Comunidade, constituindo-se como elo de referência capaz de fomentar, articular, mobilizar práticas educativas e executar ações de promoção, vigilância e controle de riscos e agravos à saúde" (EPSJV, 2002, p. 7).

Analisando de modo mais específico a concepção de educação profissional que orienta o programa, observamos que os tutores destacam a questão das competências em consonância com a proposta do Proformar, que busca no modelo de competências o referencial para a elaboração dos seus módulos programáticos. Eles enfatizam a questão das competências na sua dimensão ética e política, na perspectiva de formar um trabalhador cidadão, portanto, crítico, contextualizado e autônomo, diferente da concepção mecanicista da competência subordinada ao mercado de trabalho:

“Você está formando não só aquele que trabalha, que faz, mas você está formando um cidadão, um trabalhador que sabe o que faz, que sabe propor o seu trabalho, não precisa ser mandado. Então ele é uma pessoa crítica, que interpreta o seu meio, que sabe fazer propostas e que sabe trabalhar em diversas situações... um ser ético" (entrevistado 2). 
“Eu acho que é preciso se ter uma preocupação quando se discute competências, porque pode prevalecer o sentido de formar por competências para o mercado de trabalho, para atender o mercado e a competitividade do mercado" (entrevistado 2).

Outra questão presente no depoimento dos tutores consonante com a proposta do Proformar é a visão desse trabalhador em sua totalidade e prepará-lo para uma ação intersetorial, de acordo com o referencial da vigilância, da promoção da saúde e da educação em saúde. Os tutores expressam ainda a sua percepção sobre as inter-relações entre as competências:

“Você tem que fazer um trabalho intersetorial e romper com aquelas 'caixinhas' de trabalho fragmentado em vários departamentos e em vários setores. Então se desenvolve a pessoa, como ser humano, e não só como trabalhador" (entrevistado 2).

“Essas competências estão interligadas e caminham com o mesmo objetivo, por exemplo, o conceito de saúde, na sua visão ampliada. Isso vai permitir você trabalhar vários conceitos, dentro de uma perspectiva só, que é a perspectiva da vigilância da saúde" (entrevistado 4).

A fala dos tutores revela também a preocupação com o desenvolvimento de competências calcadas em situações concretas desse 'novo' agente, frente às transformações que se processam na sua realidade de trabalho.

“Ele vai ter que ser capaz de reconhecer inúmeras coisas que antes provavelmente não era [capaz], e a formação dele vai ser justamente fazer com que ele reconheça essas situações, seja capaz de identificar as situações e propor maneiras de solucionar, maneiras de atuação" (entrevistado 6).

Essa compreensão vem ao encontro da diretriz do Proformar de não apresentar intencionalmente um conjunto pronto de disciplinas, mas deixá-las emergir das necessidades requeridas pelas situações identificadas na experiência de trabalho do agente (EPSJV, 2002).

Alguns tutores fizeram menção a três dimensões das competências: a do fazer, a do pensar e a do sentir, abrangendo assim as competências que o Proformar classifica de técnicas, ligadas à aprendizagem do 'pensar', do 'aprender a aprender' e do 'aprender a fazer', e transversais, do 'aprender a ser':

“É muito difícil definir uma competência porque tem um conjunto de habilidades, associado a uma coisa que é mais cognitiva que é o conhecimento... Então a competência é fruto disso, da sensibilização pra ação, da habilidade em fazer, realizar aquilo, do conhecimento" (entrevistado 5). 
"A competência está muito ligada ao meu processo de conhecimento, que é aquilo que eu devo fazer, e a forma como eu devo fazer" (entrevistado 3).

No que diz respeito às competências que os agentes de saúde devem desenvolver, os tutores compreendem como mais importantes àquelas requeridas na sua relação com a população, na sua abordagem, na sua inserção na comunidade, o que implica, sobretudo, o desenvolvimento das competências transversais, embora não desprezem a importância das competências técnicas:

“A competência primeira é a competência de você saber entrar na comunidade, você saber ouvir; a ética, o sigilo, a confiança, isso eu acho que é fundamental, você adquirir essa confiança do morador. Então eu acho que a competência maior é a competência de você saber lidar com as pessoas, a questão da educação mesmo, saber ouvir e saber lidar com as pessoas, essa é a competência primeira. Depois a competência específica que é a questão relacionada ao teu trabalho, é o domínio do conhecimento" (entrevistado 4).

"Eu acho que seria a relação dele com a população, a forma de abordagem dele, uma relação direta com as famílias" (entrevistado 3).

“Competências não só técnicas, mas competências políticas, competências de relacionamento, de comunicação, estabelecer vínculos com a comunidade, então ele precisa conhecer aquela realidade, conhecer aquela população, saber chegar àquela população" (entrevistado 2).

Em síntese, os resultados da pesquisa demonstram que o propósito do Proformar de capacitar os ASP, tornando-os vigilantes ambientais críticos, é compreendido pelos tutores, entendendo que a construção da identidade do trabalhador de nível médio do SUS ocorre no seu processo de trabalho pela apreensão do território-população enquanto espaço da produção social da saúde.

Os resultados revelam, ainda, que a concepção de educação profissional presente na formulação do Proformar é apreendida pelos tutores, a qual aponta para o rompimento do conceito de competência calcado na lógica do mercado e da produção, avançando no sentido da valorização da experiência dos trabalhadores e do seu desenvolvimento como sujeitos políticos (EPSJV, 2002).

Apesar de ressignificarem alguns conceitos, construindo suas próprias idéias conforme seus conhecimentos, suas experiências, sua visão de mundo, os tutores têm concepções de educação profissional que guardam uma perfeita coerência com o que foi concebido pelo Proformar. 


\section{Considerações finais}

O Proformar apresenta-se, nesta pesquisa, como uma proposta de caráter transformador, na medida em que aponta para a mudança de paradigma da educação profissional do ASP, juntamente com a mudança de paradigma do modelo assistencial de saúde ainda vigente no país, atuando na interface da educação, do trabalho e meio ambiente com a saúde.

Quanto à educação, o programa procura romper os muros da instituição de saúde prestadora de serviço e chama a atividade de formação desse agente para o seu campo mais específico — o de uma instituição de formação de pessoal técnico de saúde; propicia, ao mesmo tempo, uma abertura no horizonte da educação profissional do ASP, em termos de sua continuidade, passando a sintonizar a proposta com as diretrizes do MEC, calcadas na nova LDB, onde se insere a legislação sobre educação profissional.

No que diz respeito ao trabalho e meio ambiente, contribui para a reconstrução do papel do trabalhador de nível médio no contexto do SUS, focalizando o processo de trabalho do ASP com um olhar holístico baseado nos princípios da integração e da participação. Propicia a esse agente o despertar para uma outra dimensão do seu trabalho - o lidar com o ambiente, voltado para a melhoria da qualidade de vida, o que na sua situação concreta de trabalho é viabilizado pela proposta da territorialização, enquanto espaço dinâmico de convivência favorável ao desenvolvimento de iniciativas ambientais locais.

No que diz respeito à saúde, colabora na construção do modelo de atenção à saúde, na perspectiva da vigilância e da promoção da saúde, direcionado para as condições de vida da população, a exigir uma ação integrada (interdisciplinar e intersetorial).

Paralelamente às observações apresentadas, identificamos algumas contradições entre as concepções da proposta do Proformar e a realidade das instituições de saúde. A interdisciplinaridade e a intersetorialidade são condições essenciais para viabilização dessa proposta, sendo consenso, no discurso, a importância de se trabalhar nessa perspectiva. A prática, porém, se revela contraditória, tanto nas políticas de intervenção por parte dos gestores do SUS, que reproduzem práticas enrijecidas de planejamento vertical e de permanência de ações dissociadas e superpostas, quanto nas de caráter técniconormativo, a partir do Ministério da Saúde, que conduz políticas ainda focalizadas em programas setoriais assistenciais e de prevenção de doenças.

Entendemos o Proformar mais como um projeto em construção (com desdobramentos imprevisíveis) do que como um programa pronto. Trata-se de uma proposta corajosa e desafiadora que, enfrentando inúmeras dificuldades, avança claramente na perspectiva de uma educação profissional que contemple, sobretudo, o trabalhador-cidadão e de um modelo de atenção à 
saúde voltado para a melhoria da qualidade de vida da população, a requerer dos atores envolvidos, entre os quais o ASP, o desenvolvimento de uma consciência crítico-ecológica, na concepção da ecocidadania.

\section{Notas}

1 Membro do Grupo de Assessoria da União Internacional de Promoção e Educação em Saúde, Oficina Regional Latino-americana (Uipes/Orla), Sub-região Brasil. Mestre em Educação pela Universidade Estácio de Sá. <dodora@superig.com.br>

2 Este artigo foi elaborado a partir da dissertação de mestrado da autora intitulada Proformar: educação profissional nas interseções do trabalho, meio ambiente, educação e saúde, que contou com a orientação da professora Neise Deluiz.

3 "Em seu sentido abrangente, a saúde é a resultante das condições de alimentação, habitação, educação, renda, meio ambiente, trabalho, transporte, emprego, lazer, liberdade, acesso e posse da terra e acesso a serviços de saúde. É assim, antes de tudo, o resultado das formas de organização social da produção, as quais podem gerar grandes desigualdades nos níveis de vida" (MS, 1987, p. 382).

4 Criada pelo Decreto ${ }^{\circ} 100$ de 16 de abril de 1991, a Funasa resultou da fusão de dois grandes órgãos do Ministério da Saúde com ações interiorizadas em todo o país: a Fundação Serviços de Saúde Pública (FSesp) e a Superintendência de Campanhas de Saúde Pública (Sucam), instituída pelo Decreto nº66.623, de 22 de maio de 1970.

5 Adotamos a sua denominação original - agente de saúde pública — para designar os profissionais de nível médio/básico pertencentes ao quadro da Funasa, que desenvolvem ações de campo em epidemiologia e controle de doenças (agente de saúde pública, agente de controle de endemias, guardas de endemias e outros). A categoria agente de saúde pública foi criada pelo Decreto 79.456 de 30 de março de 1977, dentro do Grupo Saúde Pública (Brasil, 1977).

6 Paim (2003, p. 165) conceitua modelo de assistência ou modelo de atenção à saúde, como "um dado modo de combinar técnicas e tecnologias para intervir sobre problemas de saúde (danos e/ou riscos) e atender necessidades de saúde individuais e coletivas".

7 Dentre as conferências internacionais de promoção da saúde — Ottawa 1986, Adelaide 1988, Sundsval 1991, Bogotá 1992, Jakarta 1997 e México 2000 - destacamos a $1^{a}$ Conferência Internacional sobre Promoção da Saúde (Ottawa) e a Conferência Internacional sobre Promoção da Saúde na Região das Américas (Bogotá), por terem sido reconhecidas pela Carta de Fortaleza juntamente com a Conferência de Alma-Ata, em 1978, como "marcos referenciais do conceito de saúde para todos como direito fundamental do ser humano" (Teixeira, Paim e Vilasbôas, 1998, p. 8). 


\section{Referências}

ALTVATER, Elmar. 1999. Os desafios da globalização e da crise ecológica para o discurso da democracia e dos direitos humanos. In: HELLER, Agnes et al. (orgs.). A crise dos paradigmas em ciências sociais e os desafios para o século $X X I$. Rio de Janeiro: Contratempo, p. 109-154.

BARRETO, Maurício L.; CARMO, Eduardo H. 1995. Mudanças em padrões de morbimortalidade: conceitos e métodos. In: MONTEIRO, Carlos A. (org.) Velhos e novos males da saúde no Brasil. São Paulo: Hucitec/Nepens/Usp, p. 17-30.

BARROSO, Maria A. B. 1990. Educação em Saúde no controle da malária: experiência em um assentamento de colonos na Amazônia. Monografia, Niterói: Faculdade de Educação/Faculdade de Medicina, Universidade Federal Fluminense.

BRASIL. 1977. Decreto-Lei no. 79.456, de 30 de março de 1977. Dispõe sobre o Grupo Saúde Pública, do Serviço Civil da União e outras providências. Diário Oficial da União, DF, p. 3717.

. 1988. Constituição Brasileira. Brasília: Imprensa Oficial.

1996. Lei no. 9.394, de 20 de dezembro de 1996. Estabelece as Diretrizes e Bases da Educação Nacional. Disponível em: <www.planalto.gov.br/ccivil>. Acesso em: 9 abr. 2003.

BUSS, Paulo M. 2003. Uma introdução ao conceito de promoção da saúde. In: CZERESNIA, Dina; FREITAS, Carlos M. (orgs.). Promoção da saúde: conceitos, reflexões, tendências. Rio de Janeiro: Fiocruz, p. 15-38.

CORAGGIO, José Luiz. 1996. Propostas do Banco Mundial para a educação: sentido oculto ou problema de concepção? In: TOMMASI, Lívia de; WARDE, Mirian J.; HADDAD, Sérgio. (orgs.). O Banco Mundial e as políticas educacionais. São Paulo: Cortez, p. 75-123.

CZERESNIA, Dina. 2003. O conceito de saúde e a diferença entre prevenção e promoção. In: CZERESNIA, Dina.; FREITAS, Carlos M. (orgs.). Promoção da saúde: conceitos, reflexões, tendências. Rio de Janeiro: Fiocruz, p.39-53.

DELUIZ, Neise. 1996. A globalização econômica e os desafios à formação profissional. Boletim Técnico do Senac, v. 22, n. 2, p.15-21.

2001. Qualificação, competências e certificação: visão do mundo do trabalho. Formação, n. 2, p. 5-15.

; NOVICKI, Victor. 2001. Fundamentação teórica da linha de pesquisa: meio ambiente, trabalho e políticas educacionais. Rio de Janeiro: Universidade Estácio de Sá (Mimeo).

DI PIERRO, Maria Clara. 2001. Descentralização, focalização e parceria: uma análise das tendências nas políticas públicas de educação de jovens e adultos. $E d u$ cação e Pesquisa, v. 27, n. 2, p.321-337.

EPSJV (Escola Politécnica de Saúde Joaquim Venâncio). Coordenação Geral do Programa de Formação de Agentes Locais de Vigilância em Saúde. 2001. Seminários estaduais: termo de referência. Rio de Janeiro: EPSJV, Fundação Oswaldo Cruz. (Mimeo). 2002. Oficina de tutores: termo de referência. Rio de Janeiro: EPSJV, Fundação Oswaldo Cruz. (Mimeo).

GONDIM, Grácia M. de M. Termo de referência em vigilância. Disponível em: $<$ www.fiocruz.br/epsjv/outgracia.htm>. Acesso em: 11 out. 2002.

GONDIM, Grácia M. de M.; MONKEN, Maurício. 2003. Saúde, educação, cidadania e participação: a experiência do Proformar. Trabalho, Educação e Saúde, v. 1, n. 2, p.335-353.

HIRATA, Helena. 1999. Da polarização das qualificações ao modelo da competência. In: FERRETTI, Celso et al. (orgs.). Novas tecnologias, trabalho e educação: um debate multidisciplinar. $4^{\mathrm{a}}$ ed. Petrópolis: Vozes, p.128-142.

LOUREIRO, Carlos Frederico B. 2000. Teoria social e questão ambiental: pressupostos para uma práxis crítica em educação ambiental. In: LOUREIRO, Carlos Frederico B. et al. (orgs.). Sociedade e 
meio ambiente: a educação ambiental em debate. São Paulo: Cortez, p. 13-51.

MEC (Ministério da Educação). 2001. Educação Profissional: legislação básica. Brasília: Ministério da Educação. .2000. Educação profissional: referenciais curriculares nacionais da educação profissional de nível técnico. Brasília: Ministério da Educação.

MENDES, Eugênio V. 1999. As políticas de saúde no Brasil nos anos 80: a conformação da reforma sanitária e a construção da hegemonia do projeto neoliberal. In: MENDES, Eugênio V. et al. (orgs.) Distrito Sanitário: o processo social de mudanças das práticas sanitárias do Sistema Único de Saúde. $4^{a}$ ed. São Paulo/Rio de Janeiro: Hucitec/Abrasco, p. 19-91.

MINAYO, Maria Cecília S. 2004. Prefácio. In: EPSJV. Trabalho e ambientes saudáveis. Rio de Janeiro: Escola Politécnica de Saúde Joaquim Venâncio, Fundação Oswaldo Cruz ( $1^{\circ}$ Curso de Desenvolvimento Profissional de Agentes Locais de Vigilância em Saúde, Unidade II, Módulo 4).

MS (Ministério da Saúde). 1987. Relatório final da $8^{a}$ Conferência Nacional de Saúde. Brasília: Ministério da Saúde.

PAIM, Jairnilson S. 1997. Abordagens teórico-conceituais em estudos de condições de vida e saúde: notas para reflexão e ação. In: BARATA, Rita B. (org.). Condições de vida e situação de saúde. Rio de Janeiro: Abrasco, p. 7-30.

. 2003. Vigilância da saúde: tendências de reorientação de modelos assistenciais para a promoção da saúde. In: CZERESNIA, Dina; FREITAS, Carlos M. (orgs.). Promoção da saúde: conceitos, reflexões, tendências. Rio de Janeiro: Fiocruz, p. 161-174.
PERRENOUD, Philippe. 1999. Construir as competências desde a escola. Porto Alegre: Artes Médicas Sul.

RAMOS, Marise, N. 2001a. A pedagogia das competências: autonomia ou adaptação? São Paulo: Cortez. 2001b. Qualificação, competências e certificação: visão educacional. Formação, n. 2, p. 5-15.

SOBRAL, Helena R. 2000. Globalização e meio ambiente. In: DOWBOR, Ladislau; IANNI, Octavio; RESENDE, Paulo Edgard. A. (orgs.). Os desafios da globalização. Petrópolis: Vozes, p. 141-153.

STOTZ, Eduardo N. 1994. Saúde Pública e movimentos sociais em busca do controle do destino. In: STOTZ, Eduardo N.; VALLA, Victor V. (orgs.). Educação, saúde \& cidadania Petrópolis: Vozes, p. 123-142.

TEIXEIRA, Carmem F.; PAIM, Jairnilson S.; VILASBÔAS, Ana Luiza. 1998. SUS, modelos assistenciais e vigilância da saúde. Informativo Epidemiológico do SUS, v. 7, n. 2, p. 7-25.

VALLA, Victor V.; STOTZ, Eduardo N. 1994. As respostas do movimento popular ao 'estado de emergência permanente'. In: STOTZ, Eduardo N.; VALLA, Victor V. (orgs.). Educação, saúde \& cidadania. Petrópolis: Vozes, p. 99-122.

VIANA, Ana Luíza. 1997. As políticas sociais e as políticas de saúde no contexto do processo de globalização. In: GERSCHMAN, Silvia; VIANNA, Maria Lucia W. (orgs.). A miragem da pós-modernidade. Rio de Janeiro: Fiocruz, p. 201-210.

Recebido em 26/11/2004

Aprovado em 18/01/2005 